\title{
Mobile Communication and Relational Mobilization in China
}

Liu, Jun

Published in:

Asiascape: Digital Asia

DOI:

$10.1163 / 22142312-12340003$

Publication date:

2014

Document version

Publisher's PDF, also known as Version of record

Citation for published version (APA):

Liu, J. (2014). Mobile Communication and Relational Mobilization in China. Asiascape: Digital Asia, 1(1-2), 1438. https://doi.org/10.1163/22142312-12340003 


\title{
Mobile Communication and Relational Mobilization in China*
}

\author{
Jun Liu \\ Department of Media, Cognition and Communication \\ University of Copenhagen \\ liujun@hum.ku.dk
}

\begin{abstract}
Recent studies have shown what indispensable role mobile phones play as means of mobilization in contentious politics around the world. Nevertheless, there has been no clear elaboration of how mobile phone uses translate into mobilization in contentious politics. To fill this gap, the current study employs Passy's (2003) framework of the threefold function of social ties as channels of mobilization to examine how mobile communication, embedding the dynamics of social ties, influences protest mobilization. It investigates two cases in rural and urban China in which Chinese people employed their mobile phones to mobilize participants for protests, and conducts 24 in-depth interviews with participants in these protests. Findings suggest that using mobile phones for mobilization registers the relational dynamics of social ties, which shapes participants' perceptions of given protest issues, ensures the safety of protest recruitment and mobilization in a repressive context, and generates pressure on participation, all of which contributes to the mechanism of mobilization. This study concludes with the concept of 'relational mobilization', which addresses the embedment and relevance of social ties in the process of mobile-phone-mediated mobilization and its implication for Asian countries.
\end{abstract}

\section{Keywords}

mobile phone - social ties - relational mobilization - China - guanxi - contentious politics

* The author greatly appreciates the constructive comments and detailed feedback from the two anonymous reviewers and Florian Schneider's assistance in improving the manuscript. 


\section{Introduction}

The swift proliferation of the mobile phone over the past decade has dramatically changed communication practices across the world and facilitated organization and cooperation in ways that earlier mass media have never been able to achieve (e.g. Castells et al. 2007; Katz \& Aakhus 2002; Ling 2004, 2008; Rainie \& Wellman 2012). The technological features of instantaneousness, user-friendliness, and mobility, just to mention a few, that mobile communication characterizes, have provided unprecedented opportunities for recruiting and mobilizing protests and contentions in both liberal democracies and authoritarian regimes (e.g. Allagui \& Kuebler 2011; Hermanns 2008; Howard \& Hussain 2011; Rafael 2003; Suárez 2006). Although the relevance of mobile phones as key means of mobilization is well documented in the literature, to date there has been no clear elaboration of how mobile phone uses contribute to the mechanism of mobilization in contentious politics. Especially the question of why people follow mobilization messages from their mobile phones and engage in protests and contentions remains largely unanswered. To fill this gap, the present study integrates the literature of social ties and mobilization to scrutinize mobile phone uses and mobile-phone-mediated social ties in the process of recruitment and mobilization of contentious politics. By taking as its examples two cases in China in which people employed their mobile phones as key means for protest mobilization, and by conducting 24 in-depth interviews with participants in these protests, this study first aims to specify the dimensions of mobile communication that operate in the recruitment and mobilization of contentious politics. Second, by interrogating the impact of digitally-mediated social ties (i.e. mobile-phone-mediated social ties) on protest mobilization, this study contributes to a comprehensive understanding of the role that social ties play in collective action mobilization. Third, taking mobile phone uses for mobilization in China as the case also helps advance our understanding of the emancipatory potential of digital technologies and its actualization particularly in contentious politics.

China has had the world's largest number of mobile phone subscribers since 2001, surpassing 1.18 billion by the end of July 2013. According to the Ministry of Industry and Information Technology (MIIT), this number implies that over 85 percent of the 1.3 billion Chinese people own a mobile phone today (MIIT 2013). Meanwhile, Chinese people devote a remarkable amount of time to mobile phone practices in everyday life (cnBeta 2009). The increasing ubiquity and widespread use of mobile phones in China do not just shape the way in which people cope with everyday communication activities (e.g. Chu et al. 2012), but also nourish changes in the way in which people initiate, organize, 
and coordinate popular protests and collective resistances (e.g. Liu 2013a, 2013b; Weber 2011). Just as we have already seen in other parts of the world, the mobile phone has increasingly been adopted by Chinese people as a pivotal means to mobilize a wide range of contentious activities, including mass strikes and protests in China (Barboza \& Bradsher 2010; Liu 2013b; Xie \& Zhao 2007). As an emerging yet rarely touched upon topic in both communication studies and China studies, mobile-phone-mediated protests in China offer cases worthy of closer examination for illustrating and understanding the role mobile phones play in mobilizing contentious politics.

In the following pages, I first review current scholarship on mobile phones and protest mobilizations. Second, given the literature on the relationship between social ties and mobilization in social movement studies, ${ }^{1}$ in particular Passy's (2003) framework of the threefold function of social ties as channels of mobilization, I propose to investigate how mobile communication embeds and embodies the dynamics of social ties and further influences the process of recruitment and mobilization. Third, I specify case selection, data collection, and analysis methods. Fourth, I explore the role of mobile phones in the process of protest mobilization in sample cases by specifically looking at how mobile communication registers the dynamics of social ties as facilitators of recruitment and participation in protests. This study concludes with a discussion of the contribution that mobile phones have made to the mechanism of mobilization and the implication for Asian countries.

\section{2 \\ Prior Studies on Mobile Phones and Mobilization}

The proposition that mobile phones serve as means of mobilization has drawn considerable interest from the academic community as an increasing number

1 Conceptually, the terms 'contentious politics' and 'social movement' are different from each other (e.g. Tilly \& Tarrow 2006: 8; Tarrow 2011: 6-7). This study follows McAdam, Tarrow, and Tilly's definition of 'contentious politics' as 'collective political struggle' (McAdam et al. 2001: 5), which involves contention, collective action, and politics (see also Tilly \& Tarrow 2006: 4). According to Tarrow (2011), 'contentious politics' can turn into 'social movement' and vice versa. As he argues, 'contentious politics is triggered when changing political opportunities and constraints create incentive to take action for actors who lack resources on their own ... When backed by well-structured social networks and galvanized by culturally resonant, action-oriented symbols, contentious politics leads to sustained interaction with opponents - to social movements' (ibid.: 6). In this sense, this study aims to figure out how people transform their social ties and network resources, which can become part of the dynamics of social movement, into collective political action with the aid of mobile communication. 
of contentious activities witnessed the appropriation of mobile phones for recruitment and mobilization (e.g. Ibahrine 2008; Rafael 2003; Rheingold 2008). As early as in 2002, Rheingold discussed the emergence of 'smart mobs' in virtue of the proliferation of mobile communication technologies that dramatically amplify people's organizational capability for political activism. In the following decade, the pervasive adoption of the mobile phone as a crucial means of recruitment and mobilization for protests around the globe has established this device as an indispensable resource in collective activism and contentious politics. Although studies have recognized the importance of mobile phones as means of mobilization in contentious politics (Castells et al. 2007: 185-213; Howard 2010; Hermanns, 2008; Ibahrine 2008; Qiu 2008; Suárez 2006), the contribution of mobile phone uses to the mechanism of mobilization is still less well understood.

More specifically, most studies have addressed the technological affordances, or actionable properties (Gibson 1979), of mobile phones - such as widespread accessibility, decentralized diffusion of information, high message credibility, and asynchronous communication - for mobilization (e.g. Castells et al. 2007: 188; Hermanns 2008; Rafael 2003; Rheingold 2008; Suárez 2006). Nevertheless, there is not necessarily any causal explanation between these affordances and the mechanism of mobilization. In other words, the question that remains largely unanswered is how these affordances generate different kinds of mobilization mechanisms. A few studies indicate the relevance of context and inter-media dynamics (Qiu 2008; Rafael 2003: 415) beyond mobile communication for protest mobilization. Here, the mobile phone has been regarded as more or less an instrumental tool (Qiu 2008: 51) that largely relies on external forces for legitimating mobilization messages. However, as studies persuasively argue, apart from instrumental functions, mobile communication engenders mediated ritual interaction and strengthens social cohesion within the family and the peer group (e.g. Ling \& Yttri 2002; Ling 2008). What, then, is the contribution of mobile communication to the mechanism of mobilization beyond its instrumental functions? In short, understanding the specific dimensions of mobile communication that contribute to recruitment and mobilization would be an important step towards ascertaining the theoretical mechanism underlying the effect of mobile communication on mobilization. 


\section{Social Ties and Mobilization: From Face-to-Face to Mobile-Phone- Mediated Mobilization}

To better understand the role of mobile phones as means of mobilization, this study draws lessons from social movement scholars that particularly addressed the relevance of social ties as facilitators of mobilization in contentious politics. Social movement scholars have long recognized that social ties often drive people to engage in collective actions (Diani \& McAdam 2003; Kim \& Bearman 1997; Kitts 2000; McAdam 1982, 1988; McAdam \& Paulsen 1993). According to these scholars, people join social movements or engage in contentious politics because they are asked by someone with whom they have a social tie and, given such kind of social tie, from whom they receive social support on a personal level.

Simply identifying that social ties encourage participation and mobilization, however, is not sufficient to understand the functions of social ties in recruitment and mobilization (Gould 2003: 237; McAdam 2003: 287). Instead, the key questions that should be asked are why and how social ties matter in the process of recruitment and mobilization (Passy 2003). To answer this question, studies elucidate the contributions of social ties to the mechanism of mobilization from different angles, such as tie strength (Gould 2003; McAdam \& Paulsen 1993), density and frequency (Marwell et al. 1988), and salience and centrality (Fernandez \& McAdam 1989).2 Among the many studies, Passy's (2003) work on the threefold function of social ties as channels of mobilization provides a valuable framework to understand the role of social ties in mobilization.

Beyond simply seeing social ties as 'instrumental ties enabling or constraining participation', Passy argues that they 'shape both stable aspects such as values and identities and more volatile aspects such as perceptions and preferences' (ibid.: 23). To be sure, Passy categorizes the role of social ties in the process of mobilization by differentiating between three functions: the socialization function, through which social ties enable individuals to establish their

2 Social ties refer to the relationships between the actors in a society. The tie strength, or strength of a social tie, is 'a (probably linear) combination of the amount of time, the emotional intensity, the intimacy (mutual confiding), and the reciprocal services which characterize each tie' (Granovetter 1973: 1361). The density and frequency of social ties are roughly defined by the degree of one-to-one (or 'dyadic') connections in a population. The term 'centrality' describes the relative importance of an actor in a social network, and can be measured in different ways, e.g. by degree, betweenness, closeness, and eigenvector. For further discussions of these concepts, see for instance Wasserman \& Faust (1994). 
interpretive frames, construct their identities, and consolidate political consciousness towards a given protest issue; the structural-connection function, through which social ties attach potential participants to mobilization opportunities, encouraging them to convert their political consciousness into action; and the decision-shaping function, through which social ties exert significant influence on the individual preferences or perceptions that form the very end of the process of individual decisions to participate (ibid). By doing so, Passy demonstrates the relevance of social ties not only as 'an environment that facilitates recruitment to social movements', but most importantly as 'envelopes of meanings' (ibid.: 42-43) that provide individuals with specific meaning structures (through the socialization and decision-shaping functions) which affect their participation. As a key part of mobilization, Passy addresses in her study the process of social interactions taking place among individuals with social ties, as this process facilitates both the production of meanings that are integrated into the self, and the communication of perceptions and preferences that later engages others in collective action (ibid.: 26). In short, beyond the instrumental function, social ties embody 'islands of meanings which define and redefine individual identities through their interactions with other actors or groups, but also by shaping more volatile perceptions or preferences' through 'the cultural dimension of social interaction' (ibid.: 27). As such, Passy's framework calls for a comprehensive and nuanced account of the role of social ties in the process of mobilization.

As a valuable framework for understanding social ties as facilitators of mobilization, Passy's work has yet to be employed to investigate the contribution from social ties mediated by and embedded in new communication technologies to collective actions in current 'networked' society (Rainie \& Wellman 2012). Given her framework of a threefold function of social ties in mobilization, this study aims to figure out how mobile-phone-mediated social ties work, and how they contribute to protest mobilization. Additionally, Passy's elaborations are largely based on social ties within social movement organizations (SMOs) in stable liberal and democratic contexts (2003: 28). In such settings, smos enjoy relative autonomy from the state and contribute significantly to the organization of collective action. In contrast to this, in repressive regimes like China, social organizations have been situated in a different environment and remain under the stern control of the authorities (e.g. Teets 2013). Against this backdrop, Passy predicates that social ties play a greater role in mobilization for collective actions, as they enable covert recruitment of participants and supporters in a precarious context (2003: 27). Nevertheless, she does not include any empirical evidence to support or explain this argument. Unpacking the functions of mobile-phone-mediated social ties in protest 
mobilization in the absence of smos thus also yields a comprehensive understanding of the role that social ties play in collective action mobilization.

Before moving on to the next section, it is necessary here to specify the word guanxi (关系), a key concept for the intricate social ties in Chinese culture. Guanxi connotes pervasive social ties among parties that make up a social network in Chinese society (Gold et al. 2002; Park \& Luo 2001). Beyond its literal translations as 'relation' or 'personal connections', guanxi implies intangible emotional attachments (e.g. trust and reliability) and ethical obligations established by reciprocity between two or more individuals (Christensen \& Levinson 2003: 573; Gold et al. 2002: 4). Pervading every aspect of Chinese society, guanxi have also penetrated mobile interactions (Chu et al. 2012; Chu \& Yang 2006; Wallis 2013). In a previous study (Liu 2013b: 151-177), I have therefore proposes the concept of a 'guanxi-embedded mobile social network', in which guanxi have been incorporated into both mobile communication and interpersonal networks in the wake of the increasing popularity of mobile devices and the huge rise of phone use in maintaining social ties and relations in Chinese society. To maintain consistency within the discussion, the following sections use the term 'social tie' to mean guanxi unless otherwise specified.

4

\section{Methods}

This study employs a descriptive multiple case study design (Tobin 2010) to get a nuanced picture of mobile phone uses in protest mobilization. This design also makes it possible to compare differences within and between cases, and generalize what is common across the cases (Yin 2009: 18). This study picks up the following two cases: an anti-ParaXylene ('anti-PX' for short) protest in southeast China's Xiamen city in 2007 and a mass protest in southwest China's Weng'an County in 2008.

\subsection{The Anti-PX Protest in Xiamen}

As one of the largest middle-class protests in recent years, the anti-PX protest in Xiamen has become an example of 'the power of text messaging' (Xie \& Zhao 2007), which facilitated protests and remade the public agenda. Without informing residents, local government initiated construction of a petrochemical factory that was to produce $\mathrm{PX}$, which residents later perceived as a threat to their health and well-being. To keep residents from arguing against this project, the government prevented the distribution of reports that questioned the project, censored related words on the Internet, shut down online forums 
that tried to voice opposition against the government, and asserted that the negative information about the PX project was merely 'rumour'. ${ }^{3}$ Nevertheless, the argument against the PX project was diffused and proliferated largely via mobile messages, despite government efforts to snuff out the discussion; through such messages, residents urged each other to show their dissatisfaction towards the government decision by joining a street protest. One of the most renowned texts that 'millions of Xiamen residents forwarded frenziedly via their mobile phones' over the course of three days read (Lan \& Zhang 2007; author's translation):

For the sake of our future generations, take action! Participate among 10,000 people, June 1st at 8 a.m., opposite the municipal government building! Hands tied with yellow ribbons [as a symbol for environmental protection]! Pass this message on to all your Xiamen friends!

The proliferation of mobile texts calling for protests resulted in two-day protests with over 20,000 participants. The protests had forced local government to halt the construction of the PX project immediately and relocate it six months later.

\subsection{The Weng'an Mass Incident}

Different from the environmental concern in the Xiamen case, the mass incident in Weng'an was triggered by a female student's 'unusual death' that ignited the long-standing tensions between the local government and the people (Ding 2008; Zhang et al. 2008): before the unusual death happened, forced demolition and land grabbing by local government, lack of employment, and corrupt government practices had already resulted in a deep-rooted dissatisfaction with local authority among residents (Zhao et al. 2008). After the death of the female student, local government asserted that the student had committed suicide by leaping into a river. However, her relatives refused to accept the verdict and claimed she had been raped, killed, and then tossed into the river by two male suspects, who were believed to have familial ties to the local public security bureau. The student's family went to petition the county's party committee office, but the police refused their request for an examination of the corpse. Tension mounted and claims that the student's relatives had been assaulted by the authorities instead of getting justice emerged and proliferated.

3 For instance, Phoenix Weekly, a Hong Kong-sponsored news magazine trying to bring the potentially hazardous PX project into the public eye, was quickly pulled from shelves by the authorities in Xiamen. 
Some mobile messages read: 'Without conducting a full autopsy, the police believed the female student committed suicide by jumping in a river, and they did not take mandatory measures against the suspect and ignored the family's call for a full autopsy' (Buckley 2008). Such messages ignited the public's anger as the death became intertwined with corrupt government officials, merciless policemen, and perceived injustice across the small county. Mobile texts and calls had mobilized around 10,000 people who went to the public security bureau, smashed and burned all the police vehicles parked there, and set fire to government buildings (Yu 2008).

Although these two cases took place in different settings (urban vs. rural areas), involved different groups (i.e. the middle class in Xiamen vs. the rural residents in Weng'an), and were motivated by different reasons (environmental concern vs. justice-seeking), they both embraced the mobile phone as a crucial means of organizing and facilitating protests.

After case selection, this study adopted the method of snowball sampling to recruit research subjects, and then employed in-depth interviews to investigate mobile phone uses for protest mobilization in the sample cases. Snowball sampling enables researchers to recruit individuals that are not easily accessible through other sampling strategies. Meanwhile, considering that mobile communication networks are an increasingly relevant interpersonal communication channel for social connections, they in practice lend themselves to the network-based logic of snowball sampling (e.g. Fortunati 2002; Ling 2008). Accordingly, this study locates participants in protests as interviewees by tracking the flow of mobilization messages within their mobile networks. The initial 'seeds' for sampling were by the author's friends who work as journalists or editors in local media in the two locales. Twenty-eight participants were initially recruited. Next, due to the politically sensitive nature of protest participation in China, the interviews were completely voluntary. Interviewees were also assured that the information collected would be securely stored and carefully analysed. The sample, however, has been reduced to 24 after removing those who withdrew from the research due to the sensitive subject matter. The remaining research subjects included 16 from the Xiamen case (male 9, female 7), with an average monthly salary of 5,500 RMB (900 USD), and eight from the Weng'an case (male 7 , female 1), with an average monthly salary of 2,500 RMB (408 USD).

This study used a semi-structured interview guide during focused conversations between the researcher and the interviewees to probe into the question of how participants employed their mobile phones to mobilize protests. Interviewees were asked to specify their mobile phone uses for mobilization 
and elaborate on their responses to mobilization texts or calls and the messages' impact on their perception and practices. Each interview was conducted in Chinese and lasted around one and a half hours. An explanation-building approach and cross-case synthesis (Yin 2009: 18) were employed after data collection to figure out how participants used their mobile phones to organize protests against the authorities and what the influence of mobile communication on the mechanism of mobilization is.

\section{$5 \quad$ Findings and Discussions}

\subsection{The Socialization Function of Mobile-Phone-Mediated Social Ties in Mobilization}

At the beginning of the mobilization process, the socialization function of social ties cultivates an initial proposition on how political identity and consciousness should be built towards a given protest issue. Passy especially underlines that it is through social interactions that such proposition has been established, shared, and recognized among people in a social network (2003: 23). In this study, mobile communication plays a key role in facilitating social interactions that dramatically shape people's perceptions and knowledge of politically sensitive and even censored issues in China despite government manipulation and censorship, get as many people close to the issues as possible, and engender their political consciousness for protests.

In practice, mobile interactions breached the authority-mandated information blockade, in both cases offering alternative messages to shape people's views and knowledge against the government's dominant discourse. In the Xiamen case, it was through mobile interactions that local residents were informed that a petrochemical project with potentially detrimental influence on both the environment and public health had already been under construction, that some academics had tried to propose a relocation plan of the project but had been rejected, ${ }^{4}$ and that local government intended to keep people from knowing and discussing the project by censoring any PX-related information. With the help of the mobile phone, the capacity to communicate with each other beyond face-to-face communication helped people share messages that were relevant to each other and carry out discussions through these messages regardless of censorship. In this way, social interactions facilitated by

4 Zhao Yufen, a professor of chemistry and chemical engineering, rallied the opposition against the construction of the PX project. However, local government rejected her argument and forced her to keep silence. 
mobile phones fundamentally shaped people's perceptions of the PX project and, more importantly, their attitudes towards local government. One interviewee (Xiamen, 26 September 2010) noted that after receiving the warning text message she was disappointed that the local government 'tried to hide such a relevant issue from people. 5 Another (Xiamen, 26 September 2010) recalled that, after talking with his friends via mobile phones regarding the PX project, he and his friends 'felt rather angry with a government that sacrifices people's well-being and even their lives to get benefits from such a "deleterious" project... They [the authorities] never care about our opinions!' Against this backdrop, a high degree of public anger and frustration over the government's perceived cheating practices and profit motives had been simmering, laying the foundations for later mobilization.

More importantly, as a form of interpersonal interaction on the basis of established social ties, mobile communication incorporates mutual trust and trustworthiness in social relations, and participants in these relations tend to attribute high credibility to such information. Meanwhile, the decline of social trust in China in recent years reinforces the role of social ties in everyday life, leading 'one to trust only those individuals in one's personal networks and to behave in accordance with a particularistic morality' (Yan 2009: 286). Consequently, 'to seek a new safety net, or to re-embed, the Chinese individual is forced to fall back to the family and personal network or guanxi' (ibid.: 288 , emphasis added). As this study observes, people are more likely to turn to messages from their mobile phones as the basis of their perceptions than to other information sources. For instance, the interviewees noted that they would trust those mobile messages arguing against the PX project from people within their social networks, even if 'they do not have enough background or knowledge about the topic [i.e. the PX project]' (Xiamen, 26 September 2010). It is noteworthy that the high credibility of mobile messages due to relational trust from established social ties does not mean that people take for granted that the information is fact. To be sure, one of the popular mobile texts draws an analogy between the PX project and 'an atomic bomb', highlighting its disastrous consequences for people's well-being and offspring. It is, however, impossible for people with little chemical knowledge to judge the potential effect of the project on the local environment. Here, the trustworthiness from social ties greatly enhances the perceived credibility of the information and consequently leads people to put aside the facts, or as one interviewee (Xiamen,

5 The text read '... When this massive toxic chemical product goes into production, that will mean an atomic bomb has been released over all Xiamen island. The people of Xiamen will live with leukemia and deformed babies. We want to live and we want to be healthy!' 
27 September 2010) explained: 'it's better to believe it than not, especially when messages are coming from the people you trust.' Consequently, although local government tried to advocate this project by insisting that it had already passed the assessment from national environmental agents, people still preferred to believe in the threats of 'leukemia' and 'deformed babies', both of which have indeed been directly connected to PX-related environmental pollution in the long run, but which in this case are relayed through the perceived reliable source of social ties. Such descriptions firmly made the interviewees believe that the PX project would 'ruin' the living conditions in Xiamen and destroy their well-being and that of their offspring.

Similarly, in the Weng'an case, mobile communication facilitated contested narratives about homicide suspicions regarding the female student's 'unusual death' against local authorities' claims that the girl had committed suicide. Coming from the highly-trusted information source of established social ties, such narratives convinced people that the government was trying to cover up certain unmentionable scandals, deepening the distrust between government and local residents. Such perceptions thus sparked widespread fury at the perceived corruption and tyranny of the authorities and prepared people for protest as an action against the authorities.

Furthermore, the ubiquity of mobile phones and the proliferation of mobile messages enable as many people as possible to recognize that an issue is relevant to them, engendering a broad social foundation for mobilization. In the Xiamen case, by virtue of their mobile phones, residents assured that PX-related messages quickly proliferated that would have otherwise been blocked by local authorities. In Xiamen, a city of 1.5 million people, the messages had reportedly been repeated more than 1 million times until they had reached practically every citizen there (Lan \& Zhang 2007). This feature maximizes the reach of information and broadens its influence. The extensive influence mobile communication generated has largely paved the way for the success of the protests. During the demonstration, most of the police and soldiers were simply surrounding people while indirectly giving them their support rather than blocking the protests. Some of the police were even telling people during the march to make a racket if they liked. As one local civil servant (Xiamen, 28 September 2010) admitted, 'every person already knew very well via mobile message alerts that they and their children would suffer if the Px project went ahead.'

To sum up, mobile phones play a key role in ensuring social interactions, despite government censorship, among people who share and discuss information that they feel is relevant to them. The process of sharing and disseminating messages via mobile phones entails not just information distribution as such, but also generates interpretive frames by shaping individuals' perceptions 
and knowledge about certain issues. Mobile communication thus distributes messages with high credibility through established social ties, encouraging people to trust such messages and disseminate them further, thereby continuously extending the scope of this process. The socialization function of social ties, mediated by mobile phones in this study, facilitates alternative narratives against the dominant discourse of the authorities, galvanizing widespread distrust and anger over official corruption, irresponsibility, inaction, and suppression of citizens. Such function furthermore accumulates feelings of oppression or injustice that evoke a collective identity and generates people's political consciousness for protest. In this process, given the trustworthiness from social ties, mobile communication creates 'relational credibility' for mobilization, as it reformulates a cultural model of meaning in which ultimate meaning is defined less by the content itself than by the credibility embedded in the social ties between communicators. ${ }^{6}$

\subsection{The Structural-Connection Function of Mobile-Phone-Mediated Social Ties in Mobilization}

The structural-connection function describes the role that social ties play in providing opportunities for the establishment of connections between individuals and movement, and for the realization of mobilization in action. Passy recognizes that social ties are more relevant to mobilization in repressive regimes than in liberal democracies. However, her study remains largely focused on social ties within social movement organizations in liberal contexts (2003: 33-35). What, then, is the situation in repressive regimes? More specifically, do social ties, mediated by mobile phones, have a similar structuralconnection function in China, where mobilization takes place without the involvement of movement organizations?

As this study observes, mobile communication offers unprecedented opportunities for connecting individuals to movements in China. On the one hand, the affordances mobile technologies provide empower ordinary users, even those without sufficient technical competencies to, for example, use the Internet, to mobilize people within their social networks for contentious activities in an easy but effective way. On the other hand, given the embedment of social ties in mobile communication, such communication involves reliability of personal relations and social support, including trust, solidarity, and loyalty,

6 It could be argued that this process of information perception and private accreditation is similar to Benkler's argument that digital media facilitate a 'see-for-yourself' culture (2006: 218-219). 
all of which guarantee the safety of distributing mobilization messages in a repressive context such as China.

In practice, mobile technologies provide a convenient and highly effective way for people to initiate contentious activities or mount collective resistance to the authorities through a simple and fast method - twiddling their thumbs over a mobile phone keyboard. According to the interviewees, the two following characteristics of mobile communication - inexpensiveness and immediacy - facilitate mobilization and empower users to participate in contentious activities. Inexpensiveness involves both the low-cost, easy-to-use mobile phone as the key mobilizing means and the cheap telecommunication price for information dissemination for protest mobilization, be it through voice call or text messaging. The ubiquity of mobile phones and the low-priced telecommunication fee have made this device one of the most widely used communication technologies in today's everyday life (Ling 2013). The capability of lowering the threshold for organizing and coordinating protests is accordingly immense, as mobile phones - cheaper to own and easier to run than computers - gain ground as tools for facilitating collective action and other forms of contentious politics. Meanwhile, immediacy refers to the instantaneous information transfer service via mobile phones, in particular the synchronous voice call, which enables rapid mobilization for protests. Mobile communication technologies allow for the establishment of 'perpetual contact' (Katz \& Aakhus 2002) through which each mobile user is personally addressable anytime anywhere (Ling 2008: 3). In this way, the diffusion of mobilization messages takes place instantaneously. Immediate communication means that mobilization calls proliferate within a short period, making it difficult for the authorities to predict outbursts of public dissatisfaction or intervene in potential protests. In the Xiamen case, for instance, a civil servant (Xiamen, 24 September 2010) admitted that local government never realized the mobilization text for antiPX protests would go viral merely via mobile phones and reach 'millions of residents' (Lan \& Zhang 2007) within three days, finally resulting in offline protests. Immediacy thus generates the potential for rapid mobilization, which may leave the authorities unprepared for protests. In short, mobile phones enable individuals to connect and mobilize in a low cost but rapid way, further attaching a degree of unpredictability to mobilization, which to an extent guarantees that protests unfold without intervention from the authorities.

More importantly, given the trust in and reliability of social ties, mobile communication provides participants with secure and reliable means to engage in recruitment and mobilization for protests. According to Passy, trust is a crucial driving factor behind mobilization in particular in 'situations of uncertainty' (2003: 34). In authoritarian regimes like China, both legal and 
extralegal means have become common methods for the authorities to exert harsh controls, suppress collective actions, and stifle potential mobilizations. Due to the exponentially increasing popularity of new digital media, including mobile phones and social media, the authorities are working even harder to tighten their control over digital platforms in order to curtail the possibilities of collection actions (e.g. King et al. 2013). Against this backdrop, trust from social ties has a decisive impact on the practice of distributing mobilization messages, as it guarantees that such 'forbidden contents' can be disseminated safely, even against opposition from the Chinese authorities. As one interviewee (Xiamen, 29 September 2010) elaborated,

... you have to think over to whom you would like to send such kind of information [for protest recruitment]. In particular, you have to take into consideration your mutual relationship, including the trust and reliability of the other side...Y You have to be sure that the receiver is reliable and the authorities will not be able to detect protest mobilization by being informed by the receivers in advance.

Here, mobile phones provide people with a highly secure means to identify the receiver of mobilization messages and to recruit them, as mobile communication is largely carried out on the basis of established social ties. ${ }^{7}$ In the process of recruitment, more specifically, the senders starts by looking for receivers in their personal networks, through their mobile phone directories, who they believe will respond to their appeal for protest. The higher the level of mutual trust and reliability that the recruiter attributes to the relationship, the greater their belief that their contact will participate in the protests, and the more likely it becomes that they will notify that person. Similarly, the higher the degree of mutual trust that the senders perceive, the more secure they will believe the protest organization to be, and the more likely it consequently becomes that they will deliver mobilization messages to that specific person. In contrast, to spread mobilization messages through the Internet for recruit-

7 It is necessary to note that, working together with its state-owned mobile operators (i.e. China Mobile, China Unicom, and China Telecom), the Chinese government has set up content-filtering systems, based on keywords and combinations of keywords, to block and track 'political sensitive words' in mobile networks. Nevertheless, people in practice are turning to the power of rhetoric, including 'innuendo and metaphor, parody and hyperbole', 'sarcasm and scorn through veiled gibes and wily indirection' (Yu 2011), to help them break through government keyword blocking and censorship filters. For instance, in the Xiamen case the terms 'sanbu' (stroll) and 'gouwu' (shopping) were employed as alternatives to 'demonstration' and 'protest'. 
ment is 'a rather dangerous choice', as the diffusion process is 'totally out of control' (personal communication with interviewee, 26 September 2010). One interviewee (Xiamen, 26 September 2010) explained:

\begin{abstract}
Although it [posting mobilization messages online] definitely means that your message is read by as many people as possible, you will also have to take the risk of being identified by government censors or surveillance agencies for disseminating politically sensitive information. The Internet is under stern surveillance and intense monitoring from the government.
\end{abstract}

Distributing mobilization messages through mobile phones instead represents a more reliable way to carry out recruitment and mobilization. The senders know exactly to whom they deliver mobilization messages. The receivers similarly recognize from whom the call for mobilization comes. Therefore, selecting receivers for mobilization messages is neither a random process nor a simple inclusion of all the names in a person's mobile phone directory. Instead, the consideration regarding social ties and, more precisely, the trust and reliability between sender and receiver ranks above all else. As one interviewee (Weng'an, 13 October 2010) summarizes, 'sending [mobilization] messages in a correct way is the very first step for successful protest... No one will know what you are talking about except you and the person on the other side of the phone.'

In short, the lower costs and access to easy-to-use mobilization tools make it easier for ordinary people, even those without complex digital skills, to initiate and coordinate protest movement. The immediacy lays a foundation for rapid diffusion of mobilization message, which amplifies the scale of influence of mobilization. Apart from the technological advantages, using mobile phones for mobilization is a secure and reliable process through which people connect to, recruit, and mobilize others within their social networks for protests, as it is a low profile way to initiate and coordinate protests in repressive regimes such as China. Here, mobile communication incorporates 'relational reliability', or trust and reliability from social ties between communicators, for recruitment and mobilization.

\title{
$5 \cdot 3$ \\ The Decision-Shaping Function of Mobile-Phone-Mediated Social Ties in Mobilization
}

In the final stage of mobilization, the decision-shaping function of social ties plays a critical role in driving potential participants to real-world protest. In other words, this function encourages or even 'pushes' people to move from 
intent to action. This study observes that, through its embedded social ties, mobile communication generates mutual reliability and reciprocal obligation, which entail pressure to participate in protests not just as a sort of social support but also to fulfil the duties that are attached to people's mutual relationships.

Mutual reliability refers to the perception that an individual can both appeal to and draw strength from his or her social ties, while reciprocal obligation addresses the dynamics through which the mutual reliability of individuals is realized, reassured, and reproduced (Gouldner 1960). The formation of social ties establishes a sense of mutual reliability, through which individuals gauge the support available to them from social ties and the degree to which they are integrated into a social network. The reciprocal obligation contributes to the maintenance and development of social ties, as it implies that 'each party has rights and duties' (Goulder 1960: 169, emphasis in the original) to support others in their social network. People who fail to fulfil their reciprocal obligations will instead suffer from certain social penalties (e.g. the social network resources at their disposal will be jeopardized). The feeling of obligation to respond to the request from people within one's social network, be it through face-to-face or mobile communication, maintains the reciprocal dependency of social ties and further contributes to cohesion in social life.

With the embedment of social ties in mobile communication, using mobile phones for mobilization involves a strong sense of mutual reliability and reciprocal obligation, pushing people to participate in protests to fulfil the duties and obligations that arise from their social ties. According to the interviews, when people received mobilization messages via their mobile phones, the messages reminded them on the one hand of their relationship with the senders, and on the one hand of their duties in the social network. Such feeling, generated by self-perceived duties and responsibilities given the basis of the reciprocal nature of social ties, encourages people to respond positively to requests as at once a sort of social support and as a way to fulfil their duties in the social relationship. In other words, as soon as people received mobilization messages, the first and foremost thing they recognize is not the mobilization initiative. Instead, it is the relevance of social ties and their duties in social relationships. As one interviewee (Xiamen, 26 September 2010) noted,

...the [mobilization] message is, more relevant, an appeal from your social network. In other words, the people you know or have a close relationship with are seeking your response, help, and support. How could you thrust aside this kind of appeal? 
This statement shows that the reciprocal obligation greatly shapes people's response to such appeals, encouraging people to engage in protest as a way to fulfil their duties in the social relationship.

In contrast, those who declined to respond to mobilization messages or rejected participation were considered to have failed in their duties to others within their social networks. The refusal to participate is no longer the focus of the issue here. Instead, the refusal implies 'a refusal to fulfil your duty and obligation in a social relation' (personal communication with interviewee, 21 September 2010), consequently eroding one's social ties in the long run. One interviewee (Weng'an, 26 October 2010) asked: 'If you do not react to requests from your friends, then how can you expect their help in the future?' With this in mind, people not only became engaged themselves but also recruited people within their social networks for the protests.

Furthermore, the more times people received mobilization messages from their social networks, the more 'pressure' they perceive to participate in the protests, and consequently the more willing they became to join. As one interviewee (Xiamen, 26 September 2010) elaborated, 'the multiple [mobilization] messages illustrate that the people you know all agree on this issue [to go on strikes or demonstrate]. And they are urging you to be one of them. You clearly do not want to be isolated.' As such, the fear of being isolated also plays into mobilization dynamics, making people more willing to engage in protests. Besides that, as one interviewee (Xiamen, 21 September 2010) notes, 'knowing that quite a lot of people you know have engaged in the protest [against the PX project] as I received messages [via my mobile phone] from them really strengthens the feeling of togetherness against what the government has done.' Instead of being scattered individuals, participants realize that they are in fact 'networked individuals' (Rainie \& Wellman 2012) enjoying support and solidarity from their social network. The consequent feeling of empowerment pushes more and more people to participate in the protests.

In summary, in the mobile-phone-mediated mobilization process, the decision-shaping function of social ties is largely based on relational obligation. In other words, the embedment of social ties in mobile communication, and in particular the reciprocity resulting from this, has been a pivotal facilitator for mobilization of and participation in protests. During the process of mobile interactions, the reciprocal nature of social ties engenders mutual reliability and evokes obligations on both sides, which accordingly facilitates collective action mobilization and participation. The degree of reliability further strengthens the feeling of reciprocity in protests, while the practice of reciprocity (i.e. joining the protests) secures and further intensifies mutual reliability and the feeling of solidarity during the protests. 
Mobile phones have been increasingly employed as means of mobilization for protests, in China as much as in other parts of the world. Nevertheless, the question of how mobile phone uses shape and contribute to the mechanism of mobilization is largely unspecified and under-theorized. By investigating two cases involving mobile phones as a requisite means for protest mobilization through 24 in-depth interviews, this study sheds light on the role of the mobile phone as a means of mobilizing protests. In particular, the article has examined the following two aspects: On the one hand, mobile communication technologies provide favourable affordances, such as immediate connection and rapid diffusion of mobilization messages, for protest mobilization. On the other hand, and more importantly, mobile communication embodies and registers the relational dynamics of social ties, which shapes participants' perceptions of given protest issues, ensures the safety of protest mobilization in a repressive context, and generates pressure to participate, all of which contributes to the mechanism of mobilization. To better draw out the contribution of mobile phones to mobilization, this study thus suggests that the concept of 'relational mobilization' helps address how social ties are embedded in mobile communication, and how this influences the mechanism of mobilization. This concept highlights the following three issues.

First, mobile phones enable and facilitate alternative communication beyond traditional communication channels. As the trustworthiness from social ties becomes embedded in mobile communication, such communication becomes characterized by relational credibility, which means that those engaged in mobile communication attribute high credibility to information they receive via their mobile phones. In turn, such information with high credibility dramatically shapes people's perception towards a given protest event.

Second, mobile phones enable people to mobilize and accumulate their social resources for protests in unprecedented ways that are both low profile and incredibly easy - twiddling thumbs over a mobile phone's keyboard. The trust and reliability from social ties guarantee that 'politically sensitive' mobilization messages are safely distributed in repressive regimes like China. Such guarantee, on the basis of relational reliability, to a degree allows recruitment and mobilization to be carried out without the authorities' intervention.

Third, using mobile phones for mobilization involves mutual reliability and reciprocal obligation from social ties, which encourage receivers to respond to the mobilization appeal out of a sense of a duty to their social networks. As such, mobile communication embodies relational obligation that generates pressure to participate, driving people to engage in protest. 
By addressing the relevance of social ties in mobilization, this study also has implications for future research on mobile phone uses and collective actions in Asian countries, as there are similarities in social ties and relationships among different countries in Asia. In South Korea, for instance, the words 'In-maek' or 'Yeon-jul' imply an enduring, dyadic close personal connection that provides emotional support while applying strong pressure on network members to conform (Yazawa 2006: 315). In Japan, the idea of 'Aidagara', roughly translated as interdependence, connotes mutual dependence and mutual trust between social actors (ibid.: 314). A promising question that scholars should explore as they further theorize the role of mobile phones in mobilization would be to what extent the current understanding of mobile phones as facilitators of relational mobilization can be employed to understand protests in other Asian contexts.

To sum up, this study contributes to the understanding of new communication technologies and their role in political protests in three ways: First, it highlights how the relational dynamics of social ties are embedded in mobile communication, and what function these social ties have as a driving force to mobilize participants for collective action. Second, as this study argues, beyond its instrumental function, mobile communication establishes a cultural dimension of social interaction that shapes the production of meanings and the articulation of perceptions and preferences regarding given protest issues. This dimension plays a significant role in the process of recruitment and mobilization in the absence of smos in authoritarian regimes like China. Third, as this study demonstrates, the understanding of the emancipatory potential of digital technologies and its actualization requires a synthetic approach that focuses attention on how technology and social/cultural dynamics are intertwined. Research on social media, including Facebook and Twitter, and political mobilization has also stressed, for instance, that the personalized influence of (political) content has a significant impact on collective action mobilization (e.g. Bennett 2012; Bennett \& Segerberg 2012). ${ }^{8}$ Only by examining the relational

8 This study acknowledges the emerging role of social media in collective mobilization around the world, as many studies have already documented (e.g. during the Arab Spring). Nevertheless, in the context of China the political role of social media in facilitating protests and contentions is still quite limited due to the Chinese governments' increasingly intensifying online censorship. More specifically, on the one hand, social media sites such as Facebook and Twitter have been blocked in mainland China since 2009, following fierce riots that had erupted in the Xinjiang Uyghur Autonomous Region, and that the authorities asserted were abetted by these social networking sites. On the other hand, the government constantly strives to exert its control over domestic social media websites like Weibo, the Chinese equivalent of Twitter. For instance, during the latest crackdown on Weibo under the guise of 'elimi- 
dynamics of such processes can we produce a more accurate understanding of the complex interplay between human and technological agency.

\section{References}

Allagui, Ilhem, \& Kuebler, Johanne (2011), 'The Arab Spring and the Role of ICTs'. International Journal of Communication, 5, 1435-1442.

Barboza, David, \& Bradsher, Keith (2010, June 16), 'In China, Labor Movement Enabled by Technology'. The New York Times, p. B1.

Benkler, Yochai (2006), The Wealth of Networks: How Social Production Transforms Markets and Freedom. New Haven: Yale University Press.

Bennett, W. Lance (2012), 'The Personalization of Politics: Political Identity, Social Media, and Changing Patterns of Participation'. The ANNALS of the American Academy of Political and Social Science, 644(1), 20-39.

Bennett W. Lance, \& Segerberg, Alexandra (2012), 'The Logic of Connective Action: Digital Media and The Personalization of Contentious Politics'. Information, Communication \& Society, 15(5), 739-768.

Buckley, Chris (28 June 2008), 'Girl's Death Sparks Rioting in China'. Retrieved 2 November 2012 from http://uk.reuters.com/article/latestCrisis/idUKPEK27256 220080628?sp=true.

Buckley, Chris (2013, September 11), 'Crackdown On Bloggers Is Mounted By China'. The New York Times, A4.

Castells, Manuel, Fernandez-Ardevol, Mireia, Qiu, Jack Linchuan, \& Sey, Araba (2007), Mobile Communication and Society: A Global Perspective. Cambridge: The мiт Press. Christensen, Karen, \& Levinson, David (2003), 'Guanxi'. In: Karen Christensen \& David Levinson (Eds.), Encyclopedia of Community: From the Village to the Virtual World. London: Sage (pp. 572-574).

Chu, Rodney Wai-chi, Fortunati, Leopoldina, Law, Pui-lam, \& Yang, Shanhua (Eds.) (2012), Mobile Communication and Greater China. London: Routledge.

cnBeta (2009), 'Diaochao xianshi zhongguo neidi shiyong shouji shijian quanqiu paiming disi' (Survey shows the usage time of mobile phone in mainland China ranks as

nating online rumours', the authorities detained and arrested dozens of activists and 'Big V's' influential Weibo users with verified accounts - for the content they posted online, generating chilled political discourse and leaving social media users saying they have to rein in sensitive posts for fear of detention (e.g. Buckley 2013). Against this backdrop, the use of social media to initiate and mobilize contentions and protests in China is still quite limited. Nevertheless, the understanding of the influence of social media on collective resistance in China can definitely benefit from studies on the political role of social media in other parts of the world. This, however, is not my focus in this paper. 
the world's fourth). Retrieved 6 May 2013 from http://news.imobile.com.cn/index-aview-id-67675.html.

Diani, Mario, \& McAdam, Doug (Eds.) (2003), Social Movements and Networks: Relational Approaches to Collective Action. Oxford \& New York: Oxford University Press.

Ding, Buzhi (2008, July 10), 'Weng'an, buan de xiancheng' (Weng'an, an Unpeaceful County City). Nanfang Zhoumo (Southern Weekend), p. A1.

Fernandez, Roberto, \& McAdam, Doug (1989), 'Multiorganizational Fields and Recruitment to Social Movements'. In: Bert Klandermans (Ed.), Organizing for Change: Social Movement Organizations in Europe and the United States. Greenwich: JAI Press.

Fortunati, Leopoldina (2002), 'The Mobile Phone: Towards New Categories and Social Relations'. Information, Communication \& Society, 5(4), 513-528.

Gibson, James J. (1979), The Ecological Approach to Visual Perception. London: Houghton Mifflin.

Gold, Thomas, Guthrie, Doug, \& Wank, David (2002), 'An Introduction to the Study of Guanxi'. In: Thomas Gold, Doug Guthrie \& David Wank (Eds.), Social Connections in China: Institutions, Culture, and the Changing Nature of Guanxi. Cambridge: Cambridge University Press (pp. 3-20).

Gould, Roger (2003), 'Why Do Networks Matter?'. In Mario Diani \& Doug McAdam (Eds.), Social Movements and Networks: Relational Approaches to Collective Action. Oxford \& New York: Oxford University Press (pp. 234-257).

Gouldner, Alvin W. (1960), 'The Norm of Reciprocity'. American Sociological Review, $25(2), 161-178$.

Granovetter, Mark S. (1973), 'The Strength of Weak Ties'. American Journal of Sociology, 78(6), 1360-1380.

Hermanns, Heike (2008), 'Mobile Democracy: Mobile Phones as Democratic Tools'. Politics, 28(2), 74-82.

Howard, Philip N. (2010), The Digital Origins of Dictatorship and Democracy: Information Technology and Political Islam. Oxford \& New York: Oxford University Press.

Howard, Philip N., \& Hussain, Muzammil M. (2011), 'The Role of Digital Media'. Journal of Democracy, 22(3), 35-48.

Ibahrine, Mohammed (2008), 'Mobile Communication and Sociopolitical Change in the Arab World'. In:James E. Katz (Ed.), Handbook of Mobile Communication Studies. Cambridge: The MIT Press (pp. 257-272).

Katz, James Everett, \& Aakhus, Mark (Eds.) (2002), Perpetual Contact: Mobile Communication, Private Talk, Public Performance. Cambridge: Cambridge University Press.

Kim, Hyojoung, \& Bearman, Peter S. (1997), 'The Structure and Dynamics of Movement Participation'. American Sociological Review, 62(1), 70-93. 
King, Gary, Pan, Jennifer, \& Roberts, Margaret E. (2013), 'How Censorship in China Allows Government Criticism but Silences Collective Expression'. American Political Science Review, 107(2), 1-18.

Kitts, James A. (2000), 'Mobilizing in Black Boxes: Social Networks and Participation in Social Movement Organizations'. Mobilization: An International Journal, 5(2), 241-257.

Lan, Yun, \& Zhang, Yidi (2007, May 29), 'Xiamen baiwan shimin fengchuan tongyi duanxin fandui gaowuran xiangmu' (Millions of Xiamen Residents Spread Crazily the Same SMS to Oppose High-Pollution Project), Nanfang Dushibao (Southern Metropolis Daily), p. 4.

Ling, Rich (2004), The Mobile Connection: The Cell Phone's Impact on Society. San Francisco: Morgan Kaufmann.

- (2008), New Tech, New Ties: How Mobile Communication is Reshaping Social Cohesion. Cambridge: The Mit Press.

_ (2013), Taken for Grantedness: The Embedding of Mobile Communication into Society. Cambridge: The MIT Press.

Ling, Rich, \& Yttri, Birgitte. (2002). 'Hyper-coordination via Mobile Phones in Norway'. In James E. Katz \& Mark Aakhus (Eds.), Perpetual Contact: Mobile communication, Private Talk, Public Performance. Cambridge: Cambridge University Press (pp. 139-169).

Liu, Jun (2013a), 'Mobile Communication, Popular Protests and Citizenship in China'. Modern Asian Studies, 47(3), 995-1018.

_ (2013b), Mobilized by Mobile Media - How Chinese People Use Mobile Phones to Change Politics and Democracy (PhD dissertation), University of Copenhagen, Copenhagen.

Marwell, Gerald, Oliver, Pamela E., \& Prahl, Ralph (1988), 'Social Networks and Collective Action: A Theory of Critical Mass III. American Journal of Sociology, 94(3), 502-534.

McAdam, Doug (1982), Political Process and The Development of Black Insurgency, 19301970. Chicago: University of Chicago Press.

- (1988), 'Micromobilization Contexts and Recruitment to Activism'. International Social Movement Research, 1, 125-154.

_ (2003), 'Beyond Structural Analysis: Toward a More Dynamic Understanding of Social Movements'. In: Mario Diani \& Doug McAdam (Eds.), Social Movements and Networks: Relational Approaches to Collective Action. Oxford \& New York: Oxford University Press (pp. 281-298).

McAdam, Doug, \& Paulsen, Ronnelle (1993), 'Specifying the Relationship Between Social Ties and Activism'. American Journal of Sociology, 99(3), 640-667.

McAdam, Doug, Tarrow, Sidney, \& Tilly, Charles (2001), Dynamics of Contention. Cambridge: Cambridge University Press. 
MIIT. (2013). '2013 nian 7 yuefen tongxinye jingji yunxing qingkuang' (Issues on Development of China's Telecommunications Sector in July 2013). Retrieved 22 October 2013 from http://www.miit.gov.cn/n11293472/n11293832/n11294132/n12 858447/15594768.html.

Park, Seung Ho, \& Luo, Yadong (2001), 'Guanxi and Organizational Dynamics: Organizational Networking in Chinese Firms'. Strategic Management Journal, 22(5), 455-477.

Passy, Florence (2003), 'Social Networks Matter. But How?' In: Mario Diani \& Doug McAdam (Eds.), Social Movements and Networks: Relational Approaches to Collective Action. Oxford \& New York: Oxford University Press (pp. 21-48).

Qiu, Jack Linchuan (2008), 'Mobile Civil Society in Asia: A Comparative Study of People Power II and the Nosamo Movement'. Javnost - The Public, 15(3), 39-58.

Rafael, Vicente L. (2003), 'The Cell Phone and the Crowd: Messianic Politics in the Contemporary Philippines'. Popular Culture, 15(3), 399-425.

Rainie, Lee, \& Wellman, Barry (2012), Networked: The New Social Operating System. Cambridge: The MIT Press.

Rheingold, Howard (2002), Smart Mobs: The Next Social Revolution. Cambridge: Perseus.

- (2008), 'Mobile Media and Political Collective Action'. In James E. Katz (Ed.), Handbook of Mobile Communication Studies. Cambridge: The MIT Press (pp. 225-240).

Suárez, Sandra L. (2006), 'Mobile Democracy: Text Messages, Voter Turnout, and the 2004 Spanish General Election'. Representation, 42(2), 117-128.

Tarrow, Sidney (2011), Power in Movement: Social Movements and Contentious Politics (3rd ed.). New York: Cambridge University Press.

Teets, Jessica C. (2013), 'Let Many Civil Societies Bloom: The Rise of Consultative Authoritarianism in China'. The China Quarterly, 213, 19-38.

Tilly, Charles, \& Tarrow, Sidney (2006), Contentious Politics. Oxford: Oxford University Press.

Tobin, Ruthanne (2010), 'Descriptive Case Study'. In: Albert J. Mills, Gabrielle Durepos \& Elden Wiebe (Eds.), Encyclopedia of Case Study Research. Thousand Oaks: Sage (pp. 289-290).

Wallis, Cara (2013), Technomobility in China: Young Migrant Women and Mobile Phones. New York: The NYU Press.

Wasserman, Stanley, \& Faust, Katherine (1994), Social Network Analysis: Methods and Applications. Cambridge: Cambridge University Press.

Weber, Ian (2011), 'Mobile, Online and Angry: The Rise of China's Middle-Class Civil Society?' Critical Arts: South-North Cultural and Media Studies, 25(1), 25-45. 
Xie, Liangbing, \& Zhao, Lei (2007), 'Duanxin de liliang' (The Power of Mobile Messaging). China Newsweek, 326(20), 16-17.

Yan, Yunxiang (2009), The Individualization of Chinese Society. Oxford: Berg.

Yazawa, Shujiro (2006), 'Social Networks in East Asia'. Theory, Culture \& Society, 23(2-3), 314-317.

Yin, Robert K. (2009), Case Study Research (4th ed.). London: Sage.

$\mathrm{Yu}$, Hua (2011, June 24), 'The Spirit of May 35th'. The International Herald Tribune. Retrieved 22 October 2013 from http://www.nytimes.com/2011/o6/24/opinion/ global/24iht-june24-ihtmag-hua-28.html?pagewanted=all.

Yu, Jianrong (2008), 'Shehui xiefen shijian fansi' (A Review of Anger-Venting Mass Incident). Nanfeng Chuang (South Wind View), 15, 20-22.

Zhang, Jieping, Zhu, Yixin, \& Huang, Lijian (2008), 'Guizhou fengbao beihou yincang de jianrui maodun' (Reporters and Common Folks in Weng'an). Yazhou Zhoukan (Asian Weekly), Retrieved 22 September 2013 from http://digest.creaders.net/article Viewer.php?atid=279340\&id=284868.

Zhao, Peng, Zhou, Furou, \& Liu, Wenguo (2008), 'Weng'an zhuazhu jingji diudiao minyi' (Weng'an Focused on Economy but Neglected Public Opinion). Liaowang (Outlook Weekly), Retrieved 2 September 2013 from http://cpc.people.com.cn/ GB/64093/64099/7508621.html. 